\title{
RELAÇÃO DE GÊNERO NA EDUCAÇÃO INFANTIL: APONTAMENTOS DA LITERATURA CIENTÍFICA
}

\author{
PROPORCIÓN DE GÉNERO EN LA EDUCACIÓN INFANTIL: LAS NOTAS DE \\ LA LITERATURA CIENTÍFICA
}

\section{GENDER RATIO IN CHILD EDUCATION: NOTES THE SCIENTIFIC LITERATURE}

\author{
Alessandra Cristina Bolfe GIACHINI ${ }^{1}$ \\ Andreza Marques de Castro LEÃO
}

RESUMO: O intento deste trabalho é investigar na literatura científica como as crianças aprendem sobre as relações de gênero no cotidiano institucional da educação infantil, visto que embora tenham pouca idade elas aprendem a diferenciar os atributos ditos como masculinos e femininos, e também assimilam o uso das cores, dos brinquedos diferenciados para cada sexo e os papéis atribuídos a mulheres e a homens. Essa diferenciação se enraíza de tal forma que será a base das futuras desigualdades refletidas na vida adulta. Dessa forma, as crianças vão construindo suas identidades e introjetando padrões com posturas discriminatórias que dificilmente serão modificadas. Neste cenário repousa a importância de que tanto os educadores, quanto as crianças tenham no processo educativo a oportunidade de ressignificar as relações de gênero que lhes foram atribuídos, porquanto ser homem, ser mulher ou, simplesmente, ser diferente é ser capaz de apresentar características pessoais que faz cada pessoa única e distinta.

PALAVRAS-CHAVE: Relações de gênero. Educação Infantil. Professor.

RESUMEN: La intención de este estudio es investigar en la literatura científica como los niños aprenden acerca de las relaciones de género, en la rutina institucional de la educación de la primera infancia, ya que si bien temprana edad aprenden a distinguir dichos atributos como masculino y femenino, y también entienden el uso de colores, de diferentes juguetes para cada sexo y los roles asignados a mujeres y hombres. Esta distinción se basa en una forma tal que será la base de las futuras desigualdades reflejadas en la edad adulta. Por lo tanto, los niños construirán sus identidades y los patrones de internalización de las actitudes discriminatorias que son poco probable que sean modificadas. En este escenario radica la importancia de educadores y niños hacer que el proceso educativo sea la oportunidad de replantear las relaciones de género que se les asigna, para un hombre, una mujer o, simplemente, ser diferente es ser capaz de presentar las características personales que hacen que cada persona única y distinta.

PALABRAS CLAVE: Relaciones de género. Educación infantil. Maestro.

${ }^{1}$ Professora de Ensino Infantil da rede municipal de Araraquara-Araraquara-SP- E:mail: brasil. acb.bia@ig.com.br

${ }^{2}$ UNESP- Universidade Estadual Paulista. Faculdade de Ciências e Letras- Araraquara-SP- Brasil.

14800-901-andrezaleao@fclar.unesp.br 
ABSTRACT: The child symbolic education system I established one, the determinant of representations broadcast production and gender issues. It is important to analyze que way models will be man or woman be registered are we bodies of children and education. Thus, or attempt this study and investigate the scientific literature children learn them on relations non-daily Gender institutional Gives child education, seen though few are old enough they learn differentiate you attributes appropriations the male and Female, and also understand or use of colors, two different toys for each fri and you roles attributed to women and men. This distinction is so rooted que future will be based reflected the inequalities in adulthood. In this form, your children will Constructing identities and introjecting standards with Which hardly changed Serao discriminatory positions. In this scenario rests to importance que BOTH you educators, the children to have the process education to opportunity of reframe relations gender they were assigned, I because be be woman man or simply be different and be able to present personal features que face each unique and different person.

KEYWORDS: Gender relations issues. Child education. Teacher.

\section{Introdução}

A educação infantil é a primeira etapa da educação básica e corresponde a fase que as crianças têm a oportunidade de conviver num grupo social mais amplo. Trata-se de um universo com características próprias com espaços, tempos, organizações e práticas construídas no seio das intensas relações crianças-crianças, crianças-adultos e adulto-adultos e distinto do ambiente familiar, comum para a criança até sua inserção no cenário escolar.

A inserção das crianças na vida social ocorre mediante a introdução das mesmas na escola. Neste ambiente elas têm contato com crianças oriundas das mais variadas idades, etnias, culturas, classes sociais, religiões, regiões, entre outros. É também o local no qual as distinções de gênero ocorrem de maneira evidente nos jogos, nos brinquedos, nas brincadeiras, nos vestuários, nos comportamentos aceitos ou não para os meninos e para as meninas, entre outros. Isso ocorre porque a escola não é neutra e reforça as diferenças de gênero.

Como lembra Leão (2012), a escola é uma instância que normatiza e disciplina as pessoas. A citada autora adentra mais neste assunto e traz uma ponderação de Louro (1997), pois segundo esta a escola reproduz o que acontece na sociedade, auxiliando, deste modo, a robustecer os costumes e os valores, tendo-se como exemplo, o masculino e feminino e a concepção dos estereótipos sexistas, como se existisse um padrão comportamental para homens e mulheres, e quem ficasse aquém desta concepção corresse o risco de ser considerada anormal. Sendo assim, pode-se afirmar que a escola reflete o sexismo que existe na sociedade, reproduzindo os preconceitos e as vantagens de um gênero sobre o outro, contribuindo para a construção das identidades sexuais dos alunos (LEÃO, 2012).

O que acontece na escola reflete o que se passa em muitas outras esferas da sociedade, por isso é relevante aprofundar as reflexões sobre gênero (PELÚCIO, 2014). 
A educação infantil constitui um sistema simbólico, uma destas esferas, determinante na produção e transmissão de representações de gênero.

Sendo assim, torna-se imperioso pensar como as relações sociais de gênero são processadas no contexto desta educação, isto é, de que maneira os modelos de ser homem ou ser mulher são inscritos nos corpos e na educação das crianças. Portanto, o objetivo deste trabalho é investigar na literatura científica como as crianças aprendem e expressam as relações de gênero no cotidiano institucional da educação infantil.

\section{Entrelaçamento gênero e escola}

Meninas e meninos são educados de modos muito diferentes, sejam irmãos de uma mesma família, sejam alunos sentados na mesma sala de aula, lendo os mesmos livros, escutando a mesma professora, entre outros. A diferença está nas formas aparentemente invisíveis com que familiares e educadores interagem com as crianças. Louro (2002, p.125) pontua que a "passagem pelos bancos escolares deixam marcas. Permite que se estabeleçam ou se reforcem as distinções entre os sujeitos".

As abordagens referentes a esse assunto, na maioria das vezes, estão centralizadas em discursos vigilantes e moralizantes, e, além disso, reforçam modelos de como deve ser o comportamento considerado adequado para os meninos e meninas, o que ilustra o quanto é preciso que tais discursos sejam descontruídos. As relações de gênero possibilitam ir além da questão anatômica e restrita do conceito de sexo, termo empregado para diferenciar pessoas do sexo feminino e masculino (LEÃO, 2012).

Ao discutir as relações de gênero faz-se necessário analisar como a literatura científica tem contribuído para que esse assunto torne-se cada vez mais presente e relevante. Com efeito, urge se romper com os preconceitos sexistas que insistem a se proliferar e persistir na sociedade.

Gênero é um conceito conveniente e importante, pois a todo o momento está presente na educação infantil. Este termo surgiu no universo acadêmico e recebeu diversas nuances. Leão (2012, p. 43) elucida que o conceito de gênero surge no movimento feminista, "como tentativa das feministas de dar respostas às desigualdades existentes entre homens e mulheres, as quais se pautavam pelo determinismo biológico". Pelúcio (2014) elucida que gênero é um conceito que permeia e organiza a vida social e que nasce do estreitamento com os estudos feministas que elaboraram as primeiras sistematizações teóricas e políticas questionando a opressão feminina como sendo algo natural.

De acordo com Costa (1994) há diferentes interpretações de gênero, sendo estas: gênero como uma variável binária; gênero como papéis sexuais dicotomizados; gênero como tradução de sistemas culturais; gênero como uma variável psicológica e gênero como relacional. A interpretação de gênero como variável binária (homem x mulher) enfoca a diferença sexual como determinantes na forma como homens e mulheres se comunicam. Tal conceituação entende que homens e mulheres são iguais, não considerando, assim, as particularidades de cada um. Também desconsidera as diferentes linguagens utilizadas pelos indivíduos que variam de acordo com a situação e com as necessidades. 
Ao limitar a conceituação de homens e mulheres empregando para tanto sexo masculino e feminino, respectivamente, deixa-se à margem o contexto sócio- históricocultural em que o indivíduo está inserido. Dessa forma, surge o conceito gênero, ou seja, para ultrapassar a questão fisiológica e anatômica do sexo. Pelúcio (2014) enfatiza que gênero é construído social e culturalmente, tem marcas históricas e tal como os corpos é plural.

Outra interpretação de gênero, como papéis sexuais dicotomizados, parte do pressuposto que a sociedade impõe certos 'papéis' para os homens e outros para as mulheres que vão determinar a forma como eles se veem e se relacionam entre si (SIMIÃO, 2000). Esse ponto de vista não analisa a questão do poder e acaba criando estereótipos de homem e de mulher. A diferença entre eles é ressaltada ao se estabelecer 'papéis' masculinos e femininos como algo definido.

A definição de gênero como tradução de sistemas culturais é sustentada por um grupo de teóricos, engajados em defender que homens e mulheres vivem em mundos separados. Para esse grupo, desde a infância meninos e meninas são educados para agir e se comunicar de forma diferenciada. A eles são ensinados direitos e deveres, criando assim as subculturas e quando tentam comunicar-se entre si igualmente são mal sucedidos (COSTA, 1994). A autora explica que o discurso sobre "mundos separados" põe demasiada ênfase na diferença, negligenciando as importantes semelhanças entre os seres humanos.

Outra opção que os teóricos (a maioria psicólogos) utilizam é a conceituação de gênero como uma variável psicológica. Para esse grupo de teóricos a diferença entre masculinidade e feminilidade é constituída por uma questão de grau na qual em determinada escala o mais masculino está em um extremo e o mais feminino no outro. Assim, os indivíduos se localizam nessa escala que irá defini-los como masculino ou feminino.

Costa (ibid.) ressalta que o gênero como força ou orientação psicológica continuou fundamentando noções tradicionais de masculinidade e feminilidade e terminou por fortalecer ainda mais esta distinção a que se propunha dissolver.

A visão de gênero como relacional parte do sistema social de relacionamento em que os indivíduos se encontram, dessa forma despreza a visão binária e a divisão de papéis, permitindo uma concepção dinâmica de masculinidade e feminilidade de acordo com a situação social em questão. Deste modo, permite ver a pluralidade de homens e mulheres dentro de seu contexto social, levando em consideração os vários fatores que influenciam na formação da personalidade dos sujeitos (COSTA, 1994).

Nesta mesma perspectiva, Scott (1990) ressalta a importância do aspecto relacional entre mulheres e homens. Segundo essa autora gênero é utilizado para sugerir que qualquer informação sobre as mulheres é necessariamente informação sobre os homens, que um implica o estudo do outro. Essa utilização enfatiza o fato de que o mundo das mulheres faz parte do mundo dos homens. Esse uso rejeita a validade interpretativa da ideia de esferas separadas e sustenta que estudar as mulheres de maneira isolada perpetua o mito de que uma esfera, a experiência de um sexo, tenha muito pouco ou nada a ver com o outro sexo. 
Para Costa (ibid, p.161), os gêneros passam a ser entendidos como processos também moldados por escolhas individuais e por pressões situacionais compreensíveis somente no contexto da interação social.

A partir desse ponto de vista de gênero, o contexto em que o indivíduo está inserido, as relações de poder, as crenças, as etnias, entre outros, são fatores que constituem a sua identidade e que contribuem para compreender como homens e mulheres fazem suas opções e as comunicam ao mundo.

As identidades de gênero não estão prontas ou acabadas em determinado momento, estão sempre se constituindo a partir de múltiplos discursos que normalizam, regulam e instauram saberes que produzem verdades.

Nesse sentido, Felipe e Bello (2009) enfatizam que há uma matriz heterossexual a qual,

delimita os padrões a serem seguidos e, ao mesmo tempo, paradoxalmente, fornece a pauta para as transgressões. É em referência a ela que se fazem não apenas os corpos que se conformam às regras de gênero e sexuais, mas também os corpos que as subvertem (LOURO, 2004 apud FELIPE; BELLO, 2009, p.141).

Tal matriz serve como guia para que o indivíduo se aproxime ou se afaste do padrão de homens e mulheres que possuem características normativas de como ter aspectos masculinos e femininos.

Segundo as elaborações de Felipe e Bello (ibid.), ao longo da vida os seres humanos orbitam essa "matriz heterossexual", estando algumas vezes mais próximo do que ela nos indica, outras vezes, mais distantes. Esses autores afirmam ainda que desde o nascimento as instâncias sociais fazem muitos investimentos para que as pessoas se tornem como "modelo" de masculinidade e feminilidade normatizado ou, ao menos, se aproximando dele. Em linhas gerais, esta normalidade acompanha o indivíduo desde a infância, visto que a cultura em se vive tende a padronizações que acabam definindo os modos considerados adequados e os que são desviantes.

Para Leão (2012, p. 42), o conceito de gênero "enfatiza que estas distinções entre homens e mulheres são de ordem social e construídas historicamente, não sendo, portanto, biologicamente determinadas". Desse modo, o gênero é entendido como uma construção social, histórica e cultural, constituída sobre as diferenças sexuais e as relações de poder, conflitos e contradições que maculam uma sociedade assinalada pela desigualdade. $\mathrm{O}$ mesmo acontece com o sentido da infância que vem se modificando e acaba tratando às pessoas de acordo com o gênero. Segundo Ariès (1981), a concepção de criança é um conceito historicamente construído e passou por várias formas de representações para chegar à percepção da infância dos nossos dias.

Conforme declara Kramer (2003, p.19),

a ideia de infância não existiu sempre e da mesma maneira. Ao contrário, ela aparece com a sociedade capitalista, urbanoindustrial, na medida em que mudam a inserção e o social da criança na comunidade. Se, na sociedade feudal, a criança exercia um papel produtivo direto (de adulto) assim que ultrapassa o período de alta mortalidade, na sociedade burguesa ela passa a ser alguém que precisa ser cuidada, escolarizada e preparada para a atuação futura. Este conceito de infância é, 
pois, determinado historicamente pela modificação nas formas de organização da sociedade.

A infância passa a ser concebida como uma categoria social referente à criança, em que há um espaço próprio para suas interações. A esse respeito, Sarmento (2003) declara que a construção histórica da infância foi o resultado de um processo complexo de produção de representações, de estruturações dos seus cotidianos e mundos e, especialmente, de constituição das organizações sociais para as crianças.

A criança não é um ser isolado, ela se constitui nas relações sociais, nos mais diferentes tempos e espaços presentes em sua vida. Essas vivências e convivências culturais e sociais dependem do tempo histórico em que se situam as crianças, mudando de cultura para cultura.

É também na infância que o corpo, o comportamento e as habilidades das crianças são marcados distintamente com características direcionadas à masculinidade e à feminilidade. Tais características geralmente são consideradas como naturais e se perpetuam, através das gerações, ou seja, propaga-se o comportamento que define que certas atitudes cabem aos homens e outras de menor status, às mulheres.

Ainda nessa perspectiva, Sayão (2002, p. 5) diz que, essas diferenças são engendradas nas crianças pouco a pouco por diversos mecanismos que envolvem suas interações com os adultos, as outras crianças, a televisão, o cinema, a música etc. A demarcação do que cabe aos meninos ou às meninas se inicia bem cedo e ocorre pela materialidade e também pela subjetividade. Essas relações influenciam nas elaborações que as crianças fazem sobre si, os outros e a cultura, e contribuem para compor sua identidade de gênero.

O modo como meninas e meninos expressam as relações de gênero no cotidiano institucional contribui para a construção de uma nova sociedade onde possam expressarse livremente e ser respeitadas/os em seus desejos, livres de preconceitos. Desse modo, conforme apontam Souza e Leão (2008), a escola é o ponto de encontro e de embate das diferenças, podendo ser instrumento eficaz para diminuir e prevenir o processo de exclusão social; é ainda um ambiente propício para se efetuar um trabalho de desconstrução dos tabus e preconceitos sexistas (LEÃO; RIBEIRO, 2011, p.274).

Vale frisar que as representações de gêneros produzidas e reproduzidas nos diversos contextos implicam, na maioria das vezes, em desigualdades e discriminações entre meninas e meninos, reforçando a associação única e supostamente natural entre sexo e padrões de gênero. Para Angers (2003), esse tratamento diferenciado tem um poderoso efeito na criança, pois é por meio dele que ela percebe tudo o que deve fazer para se conformar com o gênero masculino ou feminino.

É evidente que ao longo da infância, tanto os meninos como as meninas sofrem diversas formas de violência à medida que estão constituindo suas identidades. As maneiras de opressão e discriminação existentes na sociedade são complexas e variadas, e contribuem diretamente para que o padrão de homogeneidade anule a pluralidade e não respeite a singularidade de cada criança.

Fica evidente que as crianças vão se constituindo em meio a esses contextos e interações, porém, elas são frenéticas e estão descomprometidas com os conceitos e com o futuro que lhes é imposto. A criança pode ser comparada a figura de um panóptico, o 
olho que tudo vê, analisa e determina o funcionamento (FOUCAULT, 1999, apud FELIPE; BELLO, 2009, p.154).

A criança é portadora, aqui e agora, de direitos, de valores, de cultura: a cultura da infância. Ela não é apenas o nosso conhecimento sobre a infância, mas o conhecimento de como ser e como viver a infância (RINALDI, 2007 apud NASCIMENTO, 2010).

Em suma, nada melhor do que oferecer à criança oportunidades através de brincadeiras, conversas, textos, problematizar acerca das relações de gênero, mostrando que não é algo natural, comum, e sim, fruto de uma construção histórica. É claro que se pode trabalhar esse assunto de forma lúdica de maneira a desnaturalizá-lo. Pelúcio (2014, p. 100) salienta que gênero tem pouco a ver com natureza, haja vista que é um conceito atravessado por ideias políticas, sociais e culturais sendo que "desnaturalizar é pensar que gênero, esta marca fundamental da nossa existência, não é um dado biológico e pronto, mas varia de sociedade, ao longo da história".

A brincadeira, certamente, é um aporte relevante, pois é por meio dela que a criança aprende acerca do mundo em que está inserida. Momentos destinados às diversas formas de brincar, certamente fazem parte da rotina das instituições de Educação Infantil, e não poderia ser diferente, pois a brincadeira é sempre associada ao desenvolvimento infantil. Aliás, brincar é uma das formas mais consideráveis de estar no mundo e pensar sobre ele.

Ao brincar, a criança conhece o próprio corpo, os objetos e o espaço em que vive, imita o comportamento dos adultos à sua volta, assimilando valores e hábitos culturais, elabora sentimentos e situações vividas. Ademais, é brincando que a criança se desenvolve nos aspectos cognitivo, físico, motor, sócio-afetivo e psicológico.

De acordo com Morais (2004), tanto a brincadeira como os brinquedos que ela pode envolver estão marcados pela identidade cultural e por características sociais específicas de um grupo social. Diante disso, é possível dizer que ao mesmo tempo em que a brincadeira se constitui como uma característica universal, ela possui aspectos específicos que irão depender de diversos fatores, como ambientes físicos, sociais, culturais e as características da criança.

É por meio do brincar que a criança elabora suas aflições, descontentamentos e inquietações, ao mesmo tempo em que procura compreender o mundo adulto e sua identidade. O brincar é uma das formas legitimadoras na qual a criança introjeta conhecimentos e realiza vivências; além disso, ela utiliza-se do brincar para atribuir novos significados aos elementos da realidade ao qual está inserida (LEÃO et. al, 2009). A mencionada autora e seus colaboradores relatam que a brincadeira favorece a autoestima das crianças, levando-as a recriar e repensar os acontecimentos por elas vivenciados.

Nessa perspectiva, Wajskop (1995), indica que o brincar é uma maneira que as crianças têm para interpretar e assimilar o mundo, os objetos, a cultura, as relações e os afetos das pessoas. Pode-se dizer que o brincar é uma atividade de pesquisa, espontânea, criativa, almejada e desejada por si mesma e tão importante para saúde mental quanto alimento para saúde física (BONAMIGO; KUDE, 1991). 
Brincar é uma atividade primordial no desenvolvimento infantil, já que permite a construção da identidade, a assimilação da realidade pela vivência de papéis sociais e a aquisição de experiências. Ao brincar a criança se movimenta em busca de parceiro e na exploração de objetos, comunica-se com seus pares; expressa-se por meio das várias linguagens; descobre e aprende regras, aprimora sua capacidade de decidir.

A maneira como meninos e meninas se relacionam quando brincam e as atribuições que fazem associadas ao feminino e ao masculino, vão constituindo-os como sujeitos e formando suas identidades à partir dessas distinções. Assim, “(...) as crianças constroem-se como 'meninos-homens' e 'meninas-mulheres' a partir das concepções do que é proibido ou tolerado para cada um dos sexos" (LOPES; PINTO, 2008, p.6).

Por meio do brincar a criança aprende e reproduz determinadas formas de feminilidade e masculinidade. Por isso, ao se propor uma brincadeira, deve-se estar atento, pois ela poderá influenciar na atitude da criança. Caso a brincadeira sugerida esteja associada ao gênero, pode-se reforçar através dela o feminino relacionando à fragilidade, passividade, meiguice e ao cuidado. Ao masculino correspondem atributos como agressividade, força e coragem (MARTINS, 2006). Com efeito, é brincando que se reforçam estereótipos sexistas, tais como: que compete às meninas serem frágeis, passivas, a realizarem atividades domésticas, ao passo que aos meninos serem valentes, ativos, a não chorarem, entre outros.

O meio cultural e social implica na construção da identidade de gênero e, dentro dessa dimensão cultural, encontram-se os brinquedos que desde o século passado são legitimadores da masculinidade e da feminilidade, uma vez que a sociedade associa-os com o que se espera para um homem e uma mulher. Para as meninas há produtos específicos: bonecas; utensílios domésticos e eletrodomésticos (liquidificador, batedeira, panelas, fogão, entre outros); maquiagens; a maioria na cor rosa e que reforça o que socialmente sempre se exigiu da mulher - a maternidade e o cuidado doméstico; já para os meninos, carrinhos, games, espadas, bolas, armas, entre outros, fortificando a ideia do macho, viril, forte e ativo.

Nesse processo de construção de papéis masculinos e femininos, surgem preconceitos que se refletem no uso dos brinquedos. Para Brougère (ibid.) e Azevedo (1993), os estereótipos de gênero nos brinquedos relacionam-se ao fato de o universo feminino restringir-se, em grande parte, à casa, à família e o masculino, aos "carrinhos", à "lutinha", ao mundo externo, do trabalho.

Considerando a utilização dos brinquedos e brincadeiras, bem como sua importância no cotidiano da instituição de Educação Infantil, pode- se dizer que é nessa fase da educação que o processo de construção de identidades de gênero se torna mais incisivo. Geralmente as atitudes sexistas se fazem presentes nessas instituições, como por exemplo, não permitir que a menina brinque com carrinho e o menino brinque com bonecas. Existe a preocupação da menina se masculinizar e o menino, por sua vez, se feminilizar.

A todo momento o educador deve se vigiar para não cair no erro de controlar e cercear as brincadeiras das crianças, geralmente ele o faz de forma despercebida. Aliás, vale frisar que devem possibilitar que elas tenham acesso a todos os brinquedos, uma vez que não são definidores da orientação do desejo sexual. 
Wajskop (1999) expõe que a rotinização de comportamentos e práticas vão fazendo com que as coisas pareçam naturais e, ao mesmo tempo, vão disciplinando as crianças no controle de seus corpos e também de sua linguagem e pensamento.

A brincadeira de casinha, comum nas instituições de Educação Infantil, é um ótimo instrumento lúdico em que meninos e meninas devem brincar juntos, e assim exercitar os cuidados domésticos e familiares que ambos podem e devem desempenhar quando adultos.

Pode-se dizer o mesmo no que se refere às brincadeiras de boneca, que quando bem conduzidas pelos educadores, podem ser utilizadas para exercitar ludicamente o papel da maternidade junto às meninas e oportunizar aos meninos o exercício da paternidade.

Ainda em relação às atividades de faz-de-conta, as crianças devem ser livres para vivenciar situações referentes ou não ao seu contexto social. Os educadores têm a oportunidade de instigar a criatividade propondo-lhes situações inusitadas pertencentes a outras realidades. Nesse tipo de brincadeira, as crianças são capazes não só de representar a vida real, como também de transformá-la (MELLO, 2010).

Pode se dizer que os brinquedos e as brincadeiras acabam legitimando as diferenças discriminatórias, uma vez que vinculam a feminilidade e a masculinidade de acordo com o modelo imposto pela sociedade. Desse modo, as brincadeiras desempenham papéis fundamentais nas ações das crianças, pois por meio dessas brincadeiras elas reproduzem as relações sociais, exercendo, assim, suas atitudes e comportamentos frente ao que lhes são transmitidos.

No entanto, é também na brincadeira o momento em que as crianças se sentem livres para transgredir as normas que lhe são impostas social e culturalmente. As crianças não são receptoras passivas, elas reagem, respondem, recusam, transgridem e assumem posturas. Brougère (2001) afirma que a criança se apodera do universo que a rodeia para harmonizá-lo com sua própria dinâmica.

Cabe ao educador propor às crianças que brinquem juntas e assim cooperem entre si. Ademais, o adulto exerce uma função bastante significativa na brincadeira infantil, principalmente no ambiente da instituição de educação infantil porque é dele a capacidade de zelar pelo espaço da brincadeira, garantindo o tempo, os materiais diversificados e a privacidade para que as crianças possam brincar tranquilamente. Aliás, cabe ao adulto promover revezamentos de papéis, orientar quanto à solução de conflitos.

Posto isso, compete aos educadores refletirem sobre sua prática, discutir com seus pares, dialogar com as famílias, buscando compreender, conhecer e identificar não só as crianças, mas principalmente, suas atitudes. Trata-se de um olhar diferenciado para as relações de gênero nas brincadeiras e, quando isso não acontece, o que se tem é o reforço de modelos que incitam as desigualdades sexuais e a perpetuação de concepções equivocada.

As crianças vão se construindo como feminino ou masculino em suas relações sociais, conforme vivenciam diferentes práticas, discursos, representações e símbolos. Em vista disso, cabe a elas organizar e desorganizar seus espaços sociais, seus preceitos e suas formas de ser e estar no mundo. Essas construções e a sua organização são 
sempre transitórias, transformando-se juntamente com as histórias de cada sujeito, as identidades sexuais, raciais, étnicas e sociais.

Faz-se necessário reforçar a diferença que existe entre sexo e gênero, pois o primeiro é uma categoria biológica, indicando as diferenças anatômicas entre homens e mulheres. Já o segundo, nos remete a uma conotação social e introduz a percepção de que os comportamentos sociais são distintos entre homens e mulheres.

Os textos científicos a grosso modo mostram que o reforço destas diferenças são estratégias sutis empregadas socialmente por meio das diferenças instanciais sociais para que

as brincadeiras, os brinquedos, os comportamentos e as atitudes das crianças sejam moldados com a intenção de assegurar as normas de gênero, isto é, o que socialmente é esperado de meninos e meninas, assim como, de homens e mulheres.

O gênero interfere no processo de formação de identidade do sujeito, e isso ocorre desde a tenra infância, reunindo várias instâncias sócias, assim como os brinquedos, as brincadeiras, as músicas, entre outros que contribuem para que meninos e meninas aprendam a se reconhecer como pertencentes a determinado grupo.

Desde tenra idade as crianças vão aprendendo determinadas posturas, regras e papéis tradicionalmente instituídos como corretos. Aos poucos vão impregnando-se de velhas concepções preconceituosas sobre o que se espera delas nos papéis masculino e feminino. Vão percebendo a que gênero pertencem, e na maioria das vezes, as concepções que estão se formando são construídas com base nas diferenças de sexo. As crianças desenvolvem seus comportamentos pensando em corresponder às características para o que é definido como um modelo particular e homogêneo de masculinidade e feminilidade.

Desse modo, mesmo tendo pouca idade elas aprendem a diferenciar os atributos ditos como masculinos e femininos, e, também, assimilam o uso das cores, dos brinquedos diferenciados para cada sexo e os papéis atribuídos a mulheres e a homens. Essa diferenciação se enraíza de tal forma que será a base das futuras desigualdades refletidas na vida adulta. Dessa forma, as crianças vão construindo suas identidades e introduzindo padrões com posturas discriminatórias, que dificilmente serão modificadas.

Cabe frisar que o ambiente escolar acaba sendo um propulsor de habilidades distintas para meninas e meninos, manipulando comportamentos vistos como mais pertinentes para cada sexo. Este ambiente "reforça os estereótipos femininos e masculinos, os quais auxiliam na perpetuação do preconceito, do sexismo e da discriminação na sociedade" (LEÃO, 2012, p. 23). Na educação infantil as ações sexistas são transmitidas paras as crianças, salientando, com isso, os preconceitos e privilégios de um sexo sobre o outro.

Por esse motivo, é necessário questionar não só o que se ensina, mas a maneira como as crianças são ensinadas, sendo preciso um olhar mais atento para compreender que várias perspectivas existem no ambiente escolar, seja em qual nível for, e abarcam relações de gênero, raça, classe, sexualidade e etnia. A tarefa mais urgente talvez seja exatamente esta: desconfiar do que é tomado como "natural" (LOURO, 1997). 
No entanto, se é verdade que as representações de gênero são construídas histórica e socialmente, e permanecem, na maioria das vezes inalteradas, é a partir da educação infantil que encontramos um campo fértil e um espaço privilegiado para promover reflexões e, assim, mudanças que suspendam os paradigmas tradicionais e arraigados de comportamentos considerados masculinos e femininos.

Cabe aos adultos, profissionais da área da educação ou não, oferecer a esses meninos e meninas a oportunidade de serem eles mesmos e, assim, transitar por novas direções, vivenciando a infância na sua plenitude sem qualquer tipo de preconceito. Essas crianças devem ter seus direitos garantidos e suas diferenças respeitadas, ponderando os aspectos de gênero, classe, raça, etnia, religião, entre outros.

É certo que a construção da identidade de gênero nas brincadeiras se processa através de uma aprendizagem não formal e não intencional, a partir das quais as crianças aprendem e reproduzem determinadas formas de feminilidade e de masculinidade.

Deve-se considerar os significados materiais e simbólicos que representam o brincar disso ou daquilo, participar dessa ou daquela brincadeira. É necessário ir além de dizer e exemplificar que meninos brincam com bonecas e meninas com carrinhos. No entanto, essas ações são importantes para oportunizar relações de cooperação, amizade e também amenizar a hierarquia existente no gênero.

Mais uma vez vale salientar que os profissionais da educação e os adultos do convívio das crianças são atores sociais importantes, pois podem mediar as diferentes experiências e com elas tem oportunidades de desmistificar valores de hierarquia, poder e dominação de um gênero perante o outro.

Voltando à brincadeira, é a partir dela que acontecem os mais variados tipos de troca, e nela é possível descobrir e recriar novos significados. Isso representa transformar as brincadeiras em algo divertido e prazeroso como, por exemplo, brincar de maquiar o rosto, usar colar, óculos, vestir saias e observá-las ao rodopiar, usar chapéu, bigode, enfim, brincar de se enfeitar sem preocupação se a brincadeira é "de menino ou de menina", mas viabilizar a criança e o desejo que ela tem em ver o seu corpo enfeitado.

Ao brincar a criança deve romper com as fronteiras do gênero, e o educador, por sua vez, precisa deixar de lado os padrões que são considerados normais, para assim compreender que mais importante do que a aprendizagem que ocorre acerca do gênero através das brincadeiras, são as maneiras como as crianças usarão esse conhecimento no contexto das relações sociais de poder, nas quais estarão envolvidas na sua vida adulta.

Brincando as crianças conhecem o que os adultos presumem delas. E, portanto, não reproduzem simplesmente a cultura adulta, mas reinterpreta-a e reinventa-a de acordo com as situações, sempre garantindo as marcas da infância, com um jeito peculiar de ser criança. E mesmo quando o adulto é quem propõe a brincadeira, meninos e meninas conseguem ir além, ampliando, recriando e transgredindo o que lhe foi imposto, para realmente fazer daquela brincadeira um momento de satisfação.

Vale frisar que gênero é um referencial teórico social, cultural e político, pois tanto informa, como as instâncias sociais - família, escola - situam e problematizam esse assunto quando propõem o desejo de um novo encaminhamento (enfrentamento) 
no tocante a essas questões, visando medidas que realmente possam levar à transformação social.

\section{Considerações finais}

Para romper com as marcas que diferenciam os gêneros e que consequentemente levam às desigualdades, é mister discussões que incorporem o despertar dos profissionais da educação, levando-os a refletir sobre as suas práticas. Não se trata de um processo simples, ao contrário, é difícil desenredar, pois irá discutir questões relacionadas à sua própria constituição de identidade, os seus preconceitos e modos de lidar com a diversidade, uma vez que todos esses aspectos já estão cristalizados no seu modo de ser dos indivíduos. Por essa razão, é importante chamar a atenção para o fato de que apenas as discussões acerca das relações de gênero nem sempre são suficientes.

Se a intenção é, realmente, proporcionar mudança no modo como as crianças percebem as relações de gênero, deve-se, como já fora dito, promover atividades que lhes proporcionem vivências significativas nessa questão. Assim, além de garantir o reconhecimento das desigualdades que caracterizam essas relações, também será possível garantir a igualdade de papéis e funções sem discriminação entre meninos e meninas.

O desafio é fazer com que as crianças, desde a tenra idade até os outros níveis de escolaridade, reconheçam e reflitam sobre as relações intrínsecas de poder - dominação e submissão - que estão por trás dessas desigualdades, ideias e valores. Essa não é uma tarefa fácil, pois não se tem, no campo educacional, o hábito de discutir gênero, ainda mais no que se refere à apropriação da discussão de gênero a partir da masculinidade.

Nessa direção, é fundamental a implementação de políticas públicas de educação que considerem a construção de projetos educativos que abarquem as questões de gênero. Aplicar essa proposta requer pensar nos currículos, nas práticas escolares e nos métodos de ensino disponíveis não só às crianças, como também nos cursos de formação docente e nas capacitações dos profissionais da educação. Passa-se do tempo de processar as concepções e os aspectos de gênero presentes - mesmo que ocultos - no currículo e, desse modo, considerar uma nova organização de discursos que, possivelmente, provocarão novas posturas.

O processo educativo pode ser uma via de acesso para diminuir e prevenir as desigualdades de gênero que provavelmente, influenciarão diretamente na exclusão social. Por isso, é preciso o investimento de políticas públicas na educação que contemplem e valorizem as diferenças, sejam elas quais forem, e atuem com competência de maneira a se ter uma educação de qualidade. Tal educação deve proporcionar situações em que o modelo de poder- submissão, da supremacia de um gênero sobre outro, implícita nas diversas relações, seja rompido.

É importante que tanto os educadores, quanto as crianças e os jovens tenham no processo educativo a oportunidade de ressignificar as relações de gênero que lhes foram atribuídos. Ser homem, ser mulher ou, simplesmente, ser diferente é ser capaz de apresentar características pessoais que faz cada pessoa única e distinta. 
Vale frisar que é pertinente ainda problematizar o respeito pelas pessoas indiferentemente do seu gênero, etnia, idade, classe econômica, religião, etc., haja vista que os profissionais da educação, principalmente no que se refere à educação infantil, são sujeitos engendrados e possuem inevitável poder no que concerne à educação dessas crianças, podendo contribuir (ou não) na edificação de uma sociedade mais igualitária e harmônica, em que as diferenças sejam respeitadas e acolhidas.

Em linhas gerais, urge uma educação emancipatória e humana, que contribua para revelar as significações produzidas nas relações sociais, rompendo com as discriminações, desigualdades e preconceitos de gênero.

\section{Referências}

ANGERS, M. A sociologia e o conhecimento de si. Lisboa: Instituto Piaget, 2003.

ARIÈS, P. História Social da Criança e da Família. 2. ed. Rio de Janeiro: Guanabara, 1981.

AZEVEDO, R. H. S. Identidade sexual. In: RIBEIRO, M. (Org.). Educação sexual: novas idéias, novas conquistas. Rio de Janeiro: Rosa dos Tempos, 1993.

BONAMIGO, E. M. de R; KUDE, V. M. M. Brincar: brincadeira ou coisa séria? Porto Alegre: Educação \& Realidade, 1991.

BROUGÈRE, G. Brinquedo e Cultura. 4. ed. São Paulo: Cortez, 2001

COSTA, C. L. O leito de procusto: gênero, linguagem e as teorias feministas. Cadernos Pagu, Campinas, n. 2, p. 141-174, 1994.

FELIPE, J.; BELLO, A. T. Construção de comportamentos homofóbicos no cotidiano da educação infantil. In: BRASIL. Diversidade sexual na educação: problematizações sobre a homofobia nas escolas. Ministério da Educação: SECAD, 2009.

KRAMER, S. A política do pré-escolar no Brasil: arte do disfarce. Rio de Janeiro, Achiamé, 1982.

LEÃO, A. M. C. A percepção do(a)s professore(a)s e coordenadore(a)s dos cursos de Pedagogia da Unesp quanto à inserção da sexualidade e da educação sexual no currículo: analisando os entraves e as possibilidades para sua abrangência. 259f. Relatório de PósDoutorado (Sexologia e Educação Sexual), Universidade Estadual Paulista, Faculdade de Ciências e Letras, Araraquara, 2012.

LEÃO, A. M. C.; OLIVEIRA, C. D.; GARBUIO, K. O brincar na educação infantil: elementos para reflexão do professor acerca da sexualidade e das relações de gênero. In: X Congresso Estadual Paulista sobre Formação de Educadores, Águas de Lindóis. Anais.... Águas de Lindóia, 2009. 1CD Rom.

LEÃO, A. M. C.; RIBEIRO, P. R. M. Sexualidade sem trauma: trabalhando gênero e corpo com crianças de uma escola municipal de educação infantil. In: MONTEIRO, S. A. I. (org.). Educação na contemporaneidade: reflexão e pesquisa. São Carlos: Pedro \& João Editores, 2011. 
LOPES, M. de F.; PINTO, T. de O. Corpos e condutas: indicadores de gênero no universo infantil. Disponível em: <http://www.fazendogenero.ufsc.br/8/sts/ST24/Pinto-Lopes_24.pdf>. Acesso em: abr. 2012.

LOURO, G. L. Gênero, Sexualidade e Educação: uma perspectiva pós-estruturalista. Petrópolis: Vozes,1997.

LOURO, G. L. A escola e a pluralidade dos tempos e espaços. In: COSTA, M. V. (Org.). Escola Básica na virada do século: Cultura, política e currículo. 3. ed. São Paulo: Cortez, 2002.

MARTINS, L. M. A brincadeira de papéis sociais e a formação da personalidade. In: ARCE, A.; DUARTE, N. (Org.). Brincadeira de papéis sociais na educação infantil: as contribuições de Vigotsky, Leontiev e Elkonin. São Paulo: Xamã, 2006.

MELLO, A. M. Guarda-chuva 1: A construção da identidade na infância. In: MELLO, A. M. et al. (Org.). O dia a dia das creches e pré-escolas - Crônicas brasileiras. Porto Alegre: Artmed, 2010 .

NASCIMENTO, M. L. B. P. As creches como lugares de construção de culturas, relações e história (s). In: MELlO, A. M. (Org.). O dia a dia das creches e pré- escolas: crônicas brasileiras. Porto Alegre: Artemed, 2010.

PELÚCIO, L. Desfazendo o gênero. In: MISKOLCI, R.; LEITE JUNIOR, J. Diferenças na educação: outros aprendizados. São Carlos: EdUFSCAR, 2014.

SARMENTO, M. J. Imaginário e culturas da infância. In: Jornada "educação e imaginário". Universidade do Minho, Portugal, 2003.

SAYÃO, D. T. A Construção de identidades e papéis de gênero na infância: articulando temas para pensar o trabalho pedagógico da educação física na educação infantil. Pensar a Prática, v. 2,2002

SIMIÃO, D. S. Gênero no mundo do trabalho. Brasília, Mimeo, 2000.

SCOTT, J. Gênero: uma categoria útil de análise histórica. Educação \& Realidade. Porto Alegre, v. 16, n. 2, p. 5-22, jul./dez, 1990.

SOUZA, F. C.; LEÃO, A. M. C. Entre o discurso pedagógico e ideológico na escola: estereótipos de classe, raça e gênero. Anais Fazendo Gênero 8 - Corpo, Violência e Poder, Florianópolis, 2008.

WAJSKOP, G. O brincar na Educação Infantil. Cadernos de Pesquisa. São Paulo, n.92, p. 6269, fev. 1995.

WAJSKOP, G. Brincar na pré-escola. 3. ed. São Paulo: Cortez, 1999.

\section{Como referenciar este artigo}

GIACHINI, Alessandra Cristina Bolfe.; LEÃO, Andreza Marques de Castro. Relação de gênero na educação infantil: apontamentos da literatura científica. Revista IberoAmericana de Estudos em Educação, Araraquara/SP, v. 11, n.3. p. 1409-1422, 2016. Disponível em: 〈https://dx.doi.org/10.21723/riaee.v11.n3.9038〉. E-ISSN: 1982-5587. 